\title{
Regionalization of coaxial correlation diagrams for the semi-humid and semi-arid catchments in Northern China
}

\author{
QIAOLING LI, ZHIJIA LI, LIZHE CHEN \& CHENG YAO
}

College of Hydrology and Water Resources, Hohai University, Xikang Road, Nanjing, Jiangsu Province, 210098, China liqiaolinghhu@hhu.edu.cn

\begin{abstract}
This study aims to identify both hydrologically and physically similar catchments which would be the best donors for runoff prediction in ungauged catchments. For this study, eight gauged catchments located in the semi-humid and semi-arid regions of Northern China were used. Hydrological similarity was defined based on the transferability of coaxial correlation diagrams. The physical similarity among catchments was determined by a weighted Euclidean distance based on 19 catchment descriptors including catchment topography, land cover, and soil type. The overlap between hydrologically similar catchments and physically similar catchments was then analysed to identify the best donors. The results suggest that six catchments were hydrologically similar, of which four catchments were both hydrologically and physically similar. It is argued that once a reliable coaxial correlation diagram has been established, the coaxial correlation diagram can be transferred from one catchment to another for runoff prediction, provided that these catchments are physical similar.
\end{abstract}

Key words regionalization; coaxial correlation diagrams; hydrological similarity; physical similarity; semi-humid and semi-arid catchments

\section{INTRODUCTION}

The derivation of relationships between rainfall and the resulting runoff is a fundamental problem for the hydrologist (Rui, 2013a). Flow data are generally required for a reliable estimation of the relationship. This excludes a large number of locations where insufficient or no streamflow measurements are available. Therefore, many hydrologists focus on the methods allowing the transfer of hydrological information from gauged to ungauged locations, referred to as "regionalization". The most intuitive regionalization method is to identify similar or proxy catchments, and transfer a model parameter set calibrated on a gauged donor catchment to the target catchment (Sivapalan, 2003; He, 2011). Catchments having apparently similar physical characteristics are assumed to have a similar hydrological behaviour in these studies. However, this is not absolutely true in many cases (Oudin, 2010). The difficulty is how to determine the most suitable catchment characteristics and derive hydrological similarity from catchments' functional responses? A number of studies (e.g. McIntyre, 2005; Reichl, 2009) have discussed this question and a thorough review will not be undertaken here. In brief, hydrological similarity is generally defined on the basis of parameter transferability, runoff yield, flow duration curves, or baseflow indices, etc. Further research is needed to characterize hydrological similarity.

Semi-humid and semi-arid regions comprise over 1/3 of China's land surface. Rainfall and flow observation is often hampered by sparse rainfall and runoff gauge networks. Predictions of runoff are needed in such regions for flood and water resource management. At present, coaxial correlation diagrams and hydrological models are two commonly used tools for runoff prediction in China (Zhao and Zhuang, 1963; Rui, 2013b).

This study aims to identify both hydrologically and physically similar catchments which would be the best donors of coaxial correlation diagrams. Eight gauged catchments, including nested ones, in northern China were used. The methodology was primarily based on a combination of coaxial correlation diagrams and the Euclidean distance metric. The coaxial correlation diagram was adopted to avoid uncertainties arising from model complexity, over-parameterization, and inappropriate calibration strategy. In total, 19 catchment descriptors were selected, including topographic attributes, vegetation and geologic/lithologic characteristics, to determine physical similarity. Both hydrological similarity and physically similarity methods were used to identify the donor gauged catchments for the transfer of the coaxial correlation diagram. 


\section{STUDY SITES}

For regional study of the rainfall-runoff relationship preferably a large number of undisturbed data-intensive catchments located in different climate zones should be studied. However, it is difficult to obtain such data, especially in China. This study was conducted within eight catchments located in the semi-humid and semi-arid regions of northern China (Fig. 1).

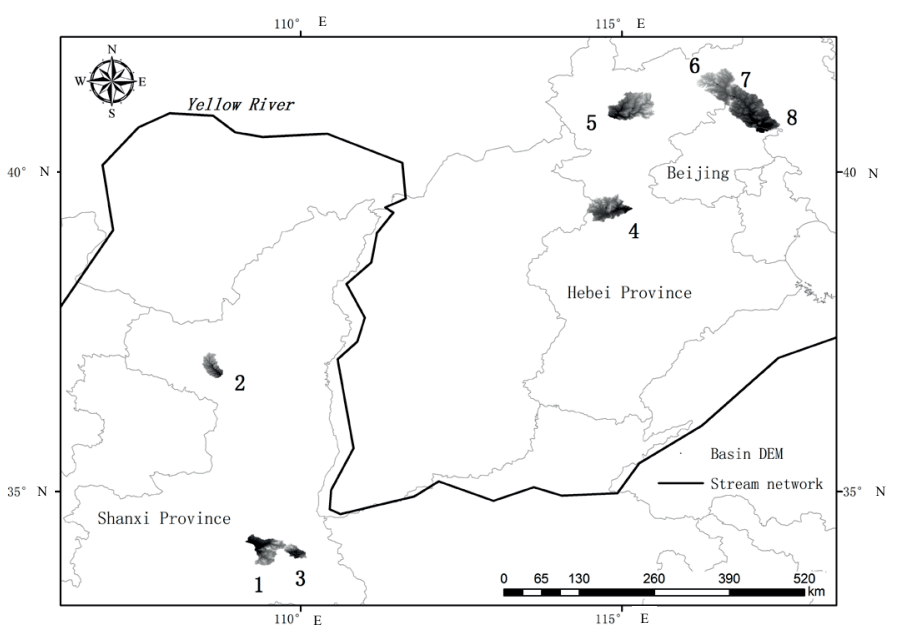

Fig. 1 Locations of the study sites.

The hydrological data of these catchments were obtained under the collaboration with the Yellow River and Hai River Conservancy Commission. The main selection criteria were accessible daily/hourly time series of rainfall and runoff of good quality to provide a range of catchment types and climatology. Table 1 lists the eight selected catchments with some of their characteristics and the period of record used for the generation of coaxial correlation diagrams. The digital elevation model (DEM) data with a spatial resolution of $90 \mathrm{~m}$, came from the website of the Chinese Academy of Sciences (http://datamirror.csdb.cn). The land cover data were derived from the Global Land Cover Database (http://www-gem.jrc.it/glc2000) with a spatial resolution of approximately $1 \mathrm{~km}$. The soil data, spatial resolution of approximately $1 \mathrm{~km}$, were derived from the digital Soil Map of China (Wu, 2003).

Table 1 Information and characteristics of the study sites.

\begin{tabular}{cllcllll}
\hline NO & Station & River System & Area $/ \mathrm{km}^{2}$ & Annual Rainfall $/ \mathrm{mm}$ & Flood events NO & Record period \\
\hline 1 & Banqiao & Yangtze River & 493 & 730 & 12 & $2000-2010$ \\
2 & Zhidan & Yellow River & 774 & 510 & 15 & $2000-2010$ \\
3 & Maduwang & Yellow River & 1601 & 630 & 10 & $2000-2010$ \\
4 & Zijingguan & Hai River & 1760 & 650 & 40 & $1956-2004$ \\
5 & Zhangjiakou & Hai River & 2300 & 393 & 20 & $1975-1985$ \\
6 & Dage & Hai River & 1850 & 432 & 44 & $1964-2008$ \\
7 & Daiying & Hai River & 4266 & 490 & 40 & $1964-2002$ \\
8 & Xiahui & Hai River & 5340 & 490 & 26 & $1979-2006$ \\
\hline
\end{tabular}

\section{METHODS}

\section{The coaxial correlation diagram}

The coaxial correlation diagram incorporates the main factors affecting the rainfall-runoff relationship with areal average rainfall and event runoff. The key of making a coaxial correlation diagram is reasonable selection of rainfall period, separation of runoff, and correct calculation of 
antecedent rainfall $P a$ etc. We calculated $P a$ for each rainfall station using equation (1) and then average antecedent rainfall for the catchment using the Thiessen polygon method. Areal average rainfall was also calculated by using the Thiessen polygon method. Event runoff was given by equation (2), assuming a linear storage relation to relate storage and discharge in a catchment.

$$
\begin{aligned}
& P_{a, t+1}=K_{a}\left(P_{a, t}+P_{t}\right) \\
& R=3.6 \Delta t\left(\sum_{i=2}^{n-1} Q_{i}+\frac{Q_{1}+Q_{n}}{2}+\left(Q_{n}-Q_{1}\right) * K\right) / A
\end{aligned}
$$

where $P_{t}$ is the amount of rainfall which occurs $t$ days prior to the event under consideration, $P_{a, t+1}$ and $P_{a, t}$ are antecedent rainfall of the $t+1$ and $t$ days respectively, $\mathrm{mm}, K_{a}$ is a recession coefficient, $R$ is event runoff, $\mathrm{mm}, Q_{i}$ is discharge at the $i$ th period, $\mathrm{m}^{3} / \mathrm{s}, \Delta t$ is the step, $h, n$ is the number of steps, $A$ is catchment area, $\mathrm{km}^{2}, K$ is a storage coefficient.

A coaxial correlation diagram was generated for each of the eight catchments making use of antecedent rainfall, rainfall during the flood event, and event runoff, which were calculated by using observed daily and hourly rainfall, and hourly discharge data. A Qualified Rate (which is obtained by the Runoff Absolute Error and Allowed Error) (Sun, 2008) was employed to assess the performance of the coaxial correlation diagrams. Comprehensive analysis was also conducted on all the eight catchments by putting all the flood event plots on one coaxial correlation diagram, to explore the regional characteristics of $(P+P a) \sim R$ and identify catchments with hydrological similarity.

\section{A physical similarity measure}

In this study, the physical similarity was defined based on comparison of such catchment descriptors as catchment shape (a form ratio and a compactness ratio), catchment structure (drainage density and the constant of channel maintenance), catchment topography (mean slope and mean elevation), land cover (forest, farmland, grass, and bush), and soil type (cambisols, luvisols, regosols, fluvisols, anthrosols, leptosols, arenosols, kastanozems, and regosols) derived from remotely sensed data. These characteristics are generally considered as the major drivers of the hydrological processes and catchment runoff response. The physical similarity among catchments was measured by means of a weighted Euclidean distance:

$$
S=1-\text { Dist }_{a, b}=1-\sqrt{\sum_{j=1}^{J} w_{j}\left(X_{a, j}-X_{b, j}\right)^{2}}
$$

where $S$ is the similarity index of catchment $a$ to catchment $b$, Dist $t_{a, b}$ is the Euclidean distance between catchment $a$ and $b, j$ indicates one of a total of $J$ catchment descriptors, $X_{a, j}$ and $X_{b, j}$ are the standardized values of that catchment descriptor at the $a$ th catchment and $b$ th catchment respectively, and $w_{j}$ is the weight attributed to the $j$ th catchment descriptor. The application of equation (3) involves measures generally having different units and scales, and therefore requires a standardization of the descriptors. The standardization was carried out by dividing each descriptor by the maximum of the descriptor: $X_{k, j}=x_{k, j} / \max \left(x_{k, j}\right)$, where $x_{k, j}$ is the value of the catchment descriptor at the $k$ th catchment before standardization. Weights were given by:

$$
w_{j}=\frac{\Delta X_{j}^{2}}{\sum_{j=1, J} \Delta X_{j}^{2}}, \text { of which } \Delta X_{j}=\frac{\sum_{k=1}^{[m / 2]} X_{k j}-\sum_{[k=m+3 / 2]}^{m} X_{k j}}{[m / 2]}
$$

where $\Delta X_{j}$ is the difference among the $j$ th descriptor of the catchments, $X_{k, j}$ is arranged in a descending order, and $m$ is the number of catchments. 


\section{RESULTS}

\section{Generation and evaluation of the coaxial correlation diagram}

Generation of the coaxial correlation diagram for each catchment We took event runoff $R$ as the abscissa, and the sum of areal average rainfall $P$ and antecedent rainfall $P a$ as longitudinal coordinates. Coaxial correlation diagrams (not shown here) were generated based on visual judgment and computer aids according to the distribution of flood events plots $\left((P+P a)_{j}, R_{j}\right)$. The performance of each coaxial correlation diagram was evaluated by a Qualified Rate $(\mathrm{QR})$ (Table 2, the upper row). The results suggest that the coaxial correlation diagram performed well with the QR values no less than $85 \%$ (the first level according to Sun, 2008) except for Banqiao with a QR value of between $60 \%$ and $70 \%$ (the third level according to Sun, 2008) and Maduwang with a QR value of between $70 \%$ and $85 \%$ (the third level according to Sun, 2008).

Generation of an integrated coaxial correlation diagram for all the catchments An integrated coaxial correlation diagram (Fig. 2) was generated according to the distribution of all the flood events plots $\left((P+P a)_{j}, R_{j}\right)$. Table 2 shows the performance based on the separated and integrated coaxial correlation diagrams respectively. The Qualified Rate values generated using the integrated coaxial correlation diagram were the same or slightly lower compared to the corresponding values produced using separated ones, with the exception of two catchments (Banqiao and Maduwang). The results suggest that the rainfall-runoff response of six catchments (Zhidan, Zijingguan, Zhangiiakou, Dage, Daiying, and Xiahui) could be represented by one common integrated coaxial correlation diagram. Theses catchments were considered hydrologically similar.

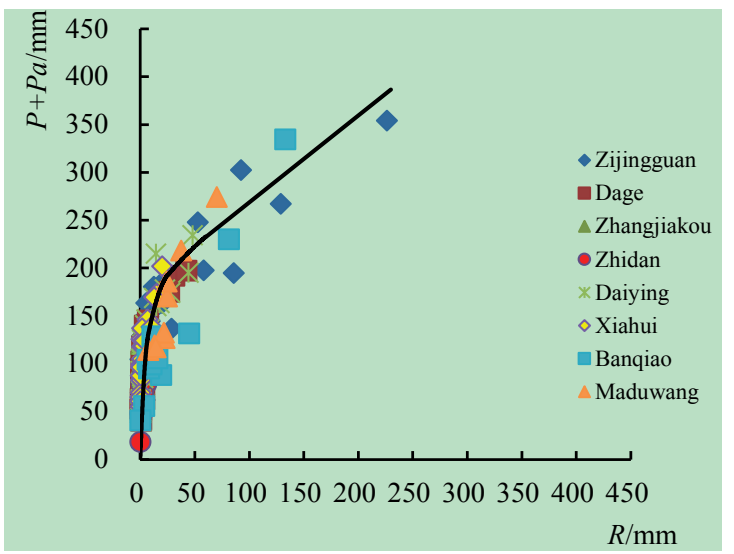

Fig. 2 Integrated coaxial correlation diagram for all the catchments

Table 2 Comparison of performance based on the separated and integrated coaxial correlation diagrams.

\begin{tabular}{lllllllll}
\hline Station no. & 1 & 2 & 3 & 4 & 5 & 6 & 7 & 8 \\
\hline Qualified rate \% (Separated) & 67 & 100 & 80 & 95 & 90 & 95 & 90 & 85 \\
Qualified rate \% (Integrated) & 42 & 100 & 30 & 90 & 90 & 93 & 82 & 81 \\
\hline
\end{tabular}

\section{Physical similarity based on catchment characteristics}

Table 3 presents the catchments' physically similarity with each other, which was determined by the distance measure defined by equation (3). High values of $S$ (greater than 0.6) are shown in bold. Banqiao and Maduwang were the catchments most similar to each other with the $S$ value of 0.65 . Zhidan and Zhangiiakou were also very similar to each other with the $S$ value being 
0.65. Four out of the eight catchments, i.e. Zijingguan, Dage, Daiying and Xiahui were similar with each other with $S$ values greater than 0.6. The results suggest that Zijingguan, Dage, Daiying and Xiahui were physically similar catchments, although Zijingguan is distant from the other three nested catchments (Dage, Daiying and Xiahui). These four catchments were both hydrologically and physically similar catchments. Any of the four catchments could be considered as ungauged (termed as pseudo ungauged). The coaxial correlation diagram could be transferred from one catchment to another within the four catchments.

Table 3 Results of catchment physical similarity with each other.

\begin{tabular}{|c|c|c|c|c|c|c|c|c|}
\hline Station & Banqiao & Zhidan & Maduwang & Zijingguan & Zhangjiakou & Dage & Daiying & Xiahui \\
\hline Banqiao & 1.00 & 0.57 & 0.65 & 0.51 & 0.49 & 0.50 & 0.50 & 0.47 \\
\hline Zhidan & & 1.00 & 0.48 & 0.48 & 0.65 & 0.37 & 0.33 & 0.31 \\
\hline Maduwang & & & 1.00 & 0.49 & 0.48 & 0.53 & 0.49 & 0.46 \\
\hline Zijingguan & & & & 1.00 & 0.46 & 0.58 & 0.62 & 0.59 \\
\hline Zhangjiakou & & & & & 1.00 & 0.44 & 0.35 & 0.33 \\
\hline Dage & & & & & & 1.00 & 0.68 & 0.68 \\
\hline Daiying & & & & & & & 1.00 & 0.95 \\
\hline Xiahui & & & & & & & & 1.00 \\
\hline
\end{tabular}

\section{DISCUSSION AND CONCLUSION}

This study has analysed the overlap between hydrologically similar catchments and physically similar catchments by using coaxial correlation diagrams and a weighted Euclidean distance. The similarities of the catchments for the transfer of coaxial correlation diagram were determined based on hydrological performance and similarity indices among catchments. Results show that four out of the eight catchments, i.e. Zijingguan, Dage, Daiying and Xiahui, were both hydrologically and physically similar catchments in term of the Qualified Rate and Similarity index. It is argued that the coaxial correlation diagram could be transferred from one catchment to another pseudo ungauged within the four catchments.

Note that six catchments (Zhidan, Zijingguan, Zhangjiakou, Dage, Daiying and Xiahui) were hydrologically similar, of which two (Zhidan and Zhangjiakou) were hydrologically similar but not physically similar with the other four catchments. Concerning the physical characteristics, some difference could be observed between these two catchments and the others. They have much lower percent of forest and luvisols than the others. Irrespective of the discrepancies in land cover and soil type, the rainfall-runoff response of these two catchments could be represented by one common integrated coaxial correlation diagram with the other four catchments (Zijingguan, Dage, Daiying and Xiahui). This was probably due to the low number of flood events in Zhidan and Zhangjiakou, which may affect the reliability of coaxial correlation diagrams. It is argued that once a reliable coaxial correlation diagram is established, the coaxial correlation diagram could be transferred from one catchment to another for runoff prediction, provided that these catchments are physically similar.

This study needs to be expanded to more basins with different rainfall-runoff behavior. The similarity index used in this study neglects the detailed spatial distribution of catchment physical characteristics. For example, we adopted mean slope but not slope distribution. However, large spatial heterogeneity exists in semi-humid and semi-arid regions. Further research is need to include the detailed spatial distribution of physical characteristics. In summary, this study presents a way of evaluating hydrological similarity for semi-humid and semi-arid regions in Northern China. The methodology proposed in this paper could be used in the identification of the donor gauged catchments for the transfer of coaxial correlation diagram to ungauged ones for runoff prediction. 
Acknowledgements We acknowledge the National Natural Science Foundation of China (41201028, 41130639, 41101017 and 51179045) for supporting this study and the anonymous reviewers for their valuable comments and suggestions.

\section{REFERENCES}

He, Y., Bárdossy, A. and Zehe, E. (2011) A review of regionalisation for continuous streamflow simulation. Hydrology and Earth System Sciences 15 (11), 3539-3553.

McIntyre, N., et al. (2005) Ensemble predictions of runoff in ungauged catchments. Water Resources Research 41 , W12434.

Oudin, L., et al. (2010) Are seemingly physically similar catchments truly hydrologically similar? Water Resources Research, W11558.

Reichl, J.P.C., et al. (2009) Optimization of a similarity measure for estimating ungauged streamflow. Water Resources Research, W10423.

Rui, X. (2013b) Discovery and development of runoff generation schemes. Advances in Science and Technology of Water Resources 33(1), 1-6

Rui, X., et al. (2013a) Present and future of hydrology. Water Science and Engineering 6(3), 241-249.

Sivapalan, M., et al. (2003) IAHS Decade on Predictions in Ungauged Basins (PUB), 2003-2012: Shaping an exciting future for the hydrological sciences. Hydrological Sciences Journal 48(6), 857-880.

Sun, J., et al. (2008) Standard for hydrological information and hydrological forecasting. Beijing: Standards Press of China, $\mathrm{GB} / \mathrm{T} 22482-2008$.

Wu, B., et al. (2003) The Land Cover Map for China in the Year 2000. GLC2000 database, European Commission Joint Research Centre.

Zhao R. and Zhuang Y. (1963) Regional law of the rainfall runoff relationship. Journal of East China Institute of Water Conservancy $1,53-68$. 